\title{
Postural Stability during Static Upright Stance in Archers
}

\section{Katerina Stambolieva ${ }^{a}$, Mihail Otzetov $^{b}$, Dorina Petrova $^{c}$, Rosen Ikonomov ${ }^{d}$ and Plamen Gatev ${ }^{a}$}

a Institute of Neurobiology, BAS, Acad. G. Bonchev Str., BI. 23, Sofia 1113, Bulgaria

${ }^{b}$ National Sports Academy, Studentski grad, Sofia 1700, Bulgaria

c Department of Neurology, Multifarious National Transport Hospital "Tzar Boris III", 108 Princess Marie Luiza Bld., Sofia 1233, Bulgaria

'Department of Neurology, Multiprofile Hospital for Active Treatment "Sofiamed", 16 G.M. Dimitrov Bld., Sofia 1797, Bulgaria

ABSTRACT: Archery is a static sport, where high postural stability, coordination of the body segments and high concentration of attention at the time of shot execution are most important to achieve high scores. We studied the postural stability of ten young male archers and fifteen healthy untrained age matched subjects during quiet and sensory-conflicted stance (standing on stable and foam support with open and closed eyes). We measured with a force platform the center of pressure excursions and calculate mean sway amplitude (MA) and mean sway velocity (SV) to evaluate static standing balance. The archers maintain the postural stability with postural sways with smaller amplitude and velocity than those of untrained subjects. We found that the visual control plays an insignificant role for keeping stable stance in archers, while the contribution of vestibular system for posture stability is substantial, especially when the visual input is switched off or proprioceptive information was altered and inadequate. The alteration of proprioception information plays a major role in keeping the static balance of archers and affects mainly the velocity of postural sway. The present results indicate that the systematic specific sport training of archers, including fixation of the posture and concentration upon the target, leads to stabilization of quiet upright stance, especially during stance on stable support compared to that of untrained subjects.

KEYWORDS: Postural control, equilibrium, archery, sensory conflict

\section{Introduction}

The upright posture is important for human motor abilities and its control is an essential requirement for physical ac- tivities in daily life. Postural control is a particularly complex system that involves the integration of various sensory and motor components. The information from the three sensory systems 
(visual, vestibular and proprioceptive) has a considerable role in standing balance. $^{1-2}$ The different sport disciplines require the different degree of postural stability and create the specific balance control strategies for keeping equilibrium. ${ }^{3}$ Sport training has significant importance for mastering the sensorimotor skills of athletes and reflects in the maintenance of their equilibrium during upright stance. There is a lot of evidence that the sporting activity changes quiet standing balance specifically for the kind of sport ${ }^{3-7}$ and this depends on the training process. Rifle shooters, for example, are trained to maintain for long time a stable upright bipedal posture, in order to stabilize the rifle, ${ }^{8}$ while gymnasts or ballet dancers reveal a great sense of the balance, especially expressed during one-legged stance. ${ }^{9-11}$ There are studies revealing that standing balance during upright stance of elite athletes (pistol and rifle shooters) is better than that of untrained subjects. ${ }^{8,12}$ There is a lack of studies of postural stability of archers. Archery is a static sport where high postural stability, coordination of the segments of the body and high concentration of attention at the time of execution of the shot are most important to achieve high scores. The purpose of this study was to evaluate postural stability of the Olympic-style archers during quiet upright stance and the effects of varying level of difficulty of the static postural task in comparison to healthy untrained subjects.

\section{Methods}

\subsection{Subjects}

Ten young male archers aged 23.04 1.31 years participated in the study ( $\mathrm{Ta}$ ble.1). They had been trained for a pe- riod over five years, three times a week. The postural stability of the athletes' group was compared with that of a control group of fifteen age matched healthy untrained subjects, who used to practice fitness activity once or twice a week only.

Table 1. Main anthropometric data of investigated subjects (mean values $\pm S D$ ).

\begin{tabular}{cccc}
\hline $\begin{array}{l}\text { Subjects } \\
\text { (expe- } \\
\text { rience) }\end{array}$ & $\begin{array}{c}\text { Age } \\
\text { (years) }\end{array}$ & $\begin{array}{c}\text { Weight } \\
\mathbf{( k g )}\end{array}$ & $\begin{array}{c}\text { Height } \\
(\mathbf{c m})\end{array}$ \\
\hline $\begin{array}{c}\text { Archers } \\
(>5\end{array}$ \\
$\begin{array}{c}\text { years) } \\
\begin{array}{c}\text { Non- } \\
\text { athletes }\end{array}\end{array}$ & $23.04 \pm 1.31$ & $78.2 \pm 11.1$ & $175.27 \pm 0.51$ \\
\hline
\end{tabular}

All subjects were without any orthopedic or neurological problems, articular and muscle trauma or injury in the past 3 months.

The study was approved by the Bioethics Committee of Institute of Neurobiology. All subjects were volunteers and gave a signed informed consent, which was co-signed by their parents as co-participants and they were free to withdraw from the study at any time.

\subsection{Experimental setup}

The evaluation of postural stability was based on the measurements of body sways described by the changes of the displacement of center of foot pressure (COP) in both anterior-posterior (AP) and medial-lateral (ML) directions.

The subjects were instructed to stand upright on the static platform with separated heels of $3 \mathrm{~cm}$ distance, feet splayed at angle of $30^{\circ}$ and arms freely hanging alongside the body. They were instructed to maintain their standing as steady as possible and to refrain from 
any voluntary movements during the 30 s recording trials. The postural sways were measured during the stance with eyes open (EO) and eyes closed (EC) in two conditions: standing on the stable surface and foam pad with dimensions of $400 \times 400 \times 150 \mathrm{~mm}$, density of 77.5 $\mathrm{kg} / \mathrm{m}^{3}$, and elastic modulus of 74.9 $\mathrm{N} / \mathrm{m}^{2}$. The foam pad was put on top of the platform to cause a postural instability by altering the proprioception. During stance with open eyes the subjects were instructed to look at a red dot $\left(1 \mathrm{~cm}^{2}\right)$ located in two meters away at eyes level. In the EC condition, the subjects were instructed to keep their gaze at a straight direction. Each trial lasted 30 seconds followed by a 30 seconds rest period.

\subsection{Data acquisition}

The postural sways were measured by a static posturographic system described previously. ${ }^{13,14}$ The signals were registered, digitized with a sampling interval of $10 \mathrm{~ms}$ and filtered with a digital Hamming low-pass filter with cut-off frequency of $10 \mathrm{~Hz}$ in order to remove the high frequency noise and sampling error. ${ }^{15}$

We used for an evaluation of the subjects' postural stability separately in the sagittal and frontal plane the sway amplitude (MA) and sway velocity (SV) measures ${ }^{16}$ for the postural sway in anterior-posterior (AP) and medial-lateral direction (ML), respectively.

\subsection{Data analysis}

The descriptive statistic was applied for all experimental variables. All continuous data (MA and SV) were explored for the normal distribution by the Kolmogorov-Smirnov test for determination of appropriate statistical methods. The dif- ference between groups was tested by the nonparametric Mann - Whitney U test. The three-way repeated measure ANOVA (general linear model repeated measure analysis of variance), design with a between-groups factor "Sport practice" (2 levels: Non-athletes and Archers) and two within-groups factors: "Vision" (2 levels: standing with open and with closed eyes) and "Support" (2 levels: stable support and foam pad). The post-hoc Newman-Keuls tests were applied and $p \leq 0.05$ was accepted as the level of statistical significance (Statistica 7.0, StatSoft Inc.,Tulsa Oklahoma, USA, 2004).

\section{Results and Discussion}

There were no significant differences of age and anthropometric data (weight and height) between investigated groups (Mann-Whitney U-test) (Table 1).

The mean sway amplitudes and velocities of postural sways for both investigated groups were presented in Fig.1 and Fig. 2.

For the MA the three ways ANOVA with repeated measures on factors "Vision" and "Surface", and a grouping factor "Sport practice" showed the significant effects of the factors "Sport practice" and "Support" as follow: "Sport practice" [AP direction (F1,23= 34.42, $\mathrm{p}<0.001)$ and $\mathrm{ML}$ direction (F1,23= 43.71, $p<0.001)$ ], "Support" [AP direction ( $F 1,23=41.2, p<0.001)$ and $M L$ direction $(F 1,23=39.36, p<0.001)]$ and their interaction - "Sport practice" $\mathrm{x}$ "Support" (F1,23= 19.01, $p<0.001)$ for ML direction only and insignificant effect of factor "Vision". The post-hoc Newman-Keuls tests revealed that:

(1) The MA value of postural sways of archers were significantly smaller than 
those of untrained subjects, except mean amplitude in stance on stable support with eyes open for AP direction (Fig.1);

(2) The negligible effect of vision on the MA of postural sways was observed for archers in both planes (AP and $M L$ ) during stance on stable support (Fig.1);

(3) The inadequate information from proprioception input leads to significant increase of the MA mean values in both planes (AP and ML) for archers, standing on foam pad with closed eyes only, compared to stable support stance. The MA mean values for the untrained subjects' group increased significantly during stance in both conditions - open and closed eyes (Fig.1).

Three ways ANOVA with repeated measures for MV showed the significant effects of the factors "Sport practice" and "Support" as follow: "Sport practice" [AP direction (F1,23= 26.31, $\mathrm{p}<0.05)$ and $\mathrm{ML}$ direction $(\mathrm{F} 1,23=17.53$, $\mathrm{p}<0.05)]$, "Support" [AP direction $(F 1,23=33.25, p<0.001)$ and $M L$ direction (F1,23=36.11, $p<0.001)$ ] and interaction - "Sport practice" x "Vision" $(F 1,23=9.71, p<0.05)$ for AP direction only. The post-hoc Newman-Keuls tests revealed that:

(1) The MV values for archers were significantly smaller than those for untrained subjects during stance on stable support with open and closed eyes $(p<0.05)$, while on stance on foam pad the significant difference observed in stance with closed eyes in AP plane only (Fig.2).

(2) The absence of vision had negligible effect of vision on the MV value for archers (Fig.2).

(3) Mean SV values for all investigated subjects while standing on foam support were significantly higher than those during stance on stable support (Fig.2).

In general, the results of this study suggest differences in keeping the postural stability between archers and untrained subjects. The archers maintain postural stability with postural sways with smaller amplitude and velocity than those of untrained subjects. We found that visual control plays an insignificant role for keeping the stable stance in archers, while the contribution of vestibular system for posture stability is higher, especially when the visual input is switched off or proprioceptive sense is altered. The changes of proprioception input information play a major role in keeping the static balance of archers and affecting dominantly the velocity of postural sway. Our results are in agreement with the findings of Era $P$ et al. $1996^{17}$ and Mononen K et al. $2007^{12}$ for smaller role of visual control for shooters (pistol and rifle shooting) in postural control.

Archery is a sport where balance is required to achieve high scores. Postural stability is one of the most important factors that determine performance in shooting sports.

The present results indicate that the systematic specific sport training of archers, including fixation of the posture and concentration upon the target, leads to stabilization of quiet upright stance, especially during stance on stable support, compared to that of untrained subjects.

\section{Acknowledgements}

The study was partly supported by the National Fund for Scientific Research, Grant TK_02/60. 


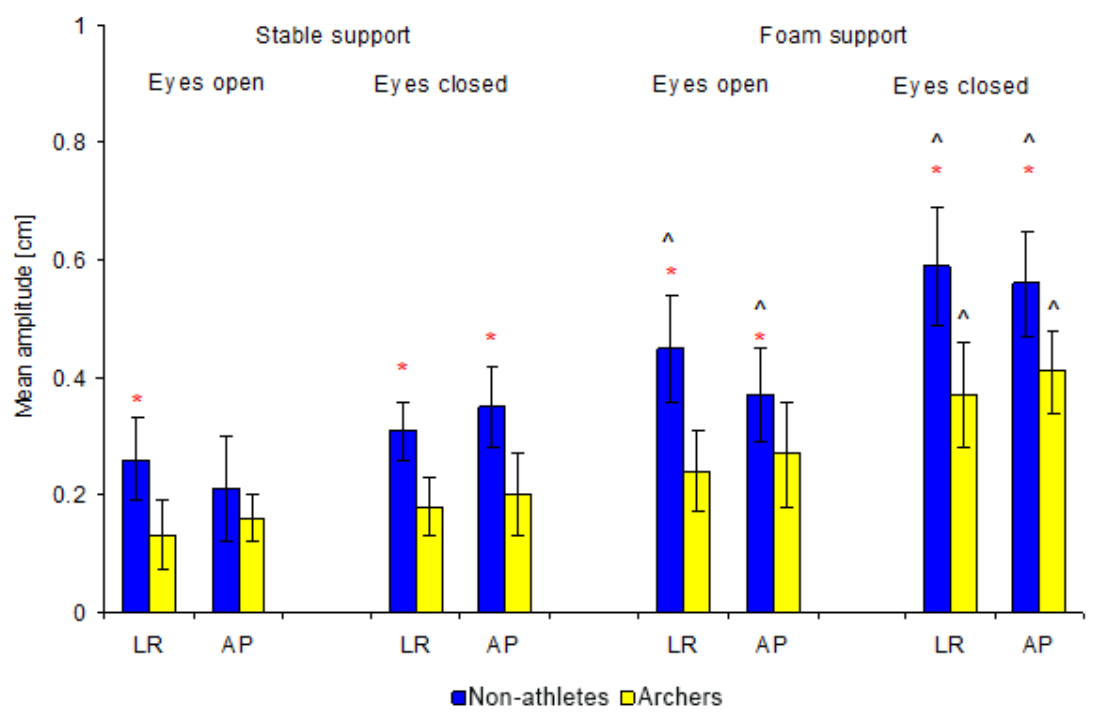

Figure 1: Mean values of postural sway amplitude (MA) +/- SD during quiet stance on stable and foam support, with open and closed eyes in the anterior-posterior (AP) and medial-lateral (ML) directions for the investigated groups: untrained subjects and archers. Significant differences $(p<0.05)$ are noted by: ${ }^{*}$ - comparisons of archers vs. untrained subjects and $\wedge$ foam vs. stable support.

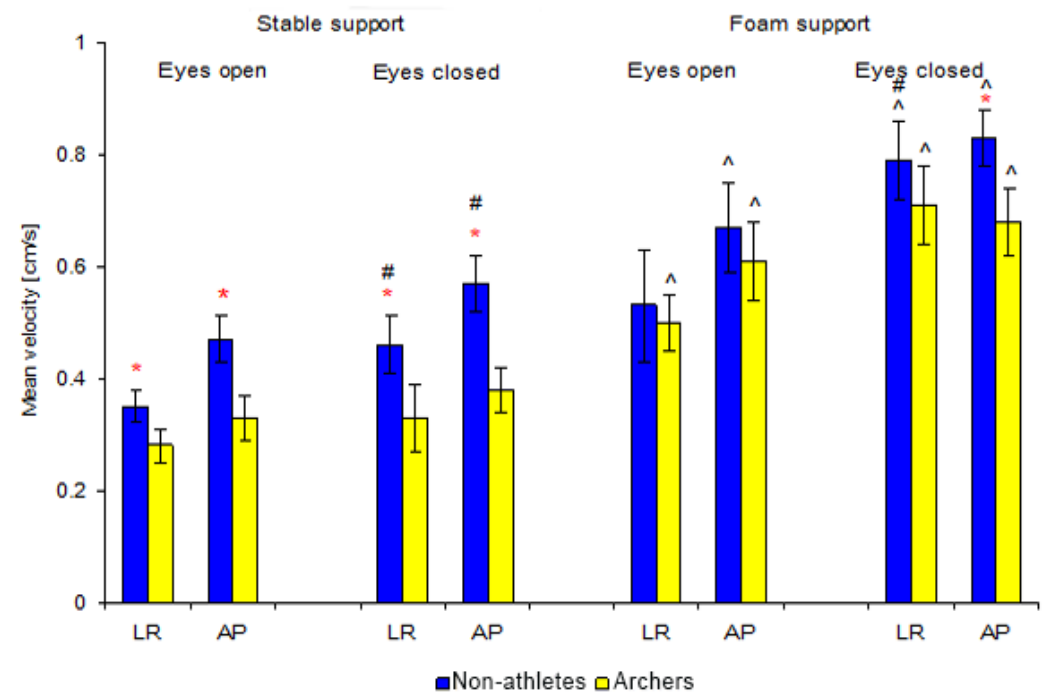

Figure 2: Mean values of postural sway velocity (MV) +/- SD during quiet stance on stable and foam support, with open and closed eyes in the anterior-posterior (AP) and medial-lateral (ML) directions for the investigated groups: untrained subjects and archers. Significant differences $(p<0.05)$ are noted by: ${ }^{*}$ - comparisons of archers vs. untrained subjects, \# closed eyes vs. open eyes and $\stackrel{\wedge}{\text { - foam }}$ vs. stable support. 


\section{References}

1. Horak F, Nashner L, Diener H. Postural strategies associated with somatosensory and vestibular loss. Exp Brain Res. 1990 Aug; 82(1):167-77. doi: 10.1007/BF00230848.

2. Massion J. Postural control system. Curr Opin Neurobiol. 1994 Dec;4(6):87787.

3. Bressel E, Yonker JC, Kras J, et al. Comparison of static and dynamic balance in female collegiate soccer, basketball, and gymnastics athletes. I Athl Train. 2007 Jan-Mar;42(1):42-6.

4. Nagy E, Toth $K$, Janositz $G$, et al. Postural control in athletes participating in an ironman triathlon. Eur J Appl Physiol. 2004 Aug;92(4-5):407-13. doi: 10.1007/ s00421-004-1157-7.

5. Gerbino P, Griffin E, Zurakowski D. Comparison of standing balance between female collegiate dancers and soccer players. Gait Posture. 2007 Oct;26(4):501-7. doi: 10.1016/j.gaitpost. 2006.11.205.

6. Ford KR, Hewett TE, Paterno MV, et al. Neuromuscular training improves single-limb stability in young female athletes. J Orthop Sports Phys Ther. 2004 Jun;34(6):305-16. doi: 10.2519/ jospt.2004.34.6.305.

7. Perrin $P$, Deviterne $D$, Hugel $F$, et al. Judo, better than dance, develops sensorimotor adaptabilities involved in balance control. Gait Posture. 2002 Apr;15(2):187-94. doi:10.1016/S09666362(01)00149-7.

8. Aalto H, Pyykkö I, Ilmarinen R, et al. Postural stability in shooters. ORL J Otorhinolaryngol Relat Spec. 1990;52(4): 232-8. doi: 10.1111/j.1600-0838.2006. 00549.x.
9. Hugel F, Cadopi M, Kohler F, Perrin P. Postural control of ballet dancers: a specific use of visual input for artistic purposes. Int J Sports Med. 1999 Feb;20(2):86-92. doi: 10.1055/s-2007971098.

10. Vuillerme N, Danion F, Marin L, et al. The effect of expertise in gymnastics on postural control. Neurosci Lett. 2001 May 4;303(2):83-6. doi: 10.1016/S03043940(01)01722-0.

11. Matsuda S, Demura S, Uchiyama M. Centre of pressure sway characteristicsduring static one-legged stance of athletes from different sports. J Sports Sci. 2008 May;26(7):775-9. doi: 10.1080/ 02640410701824099.

12. Mononen K, Konttinen N, Viitasalo $J$, et al. Relationships between postural balance, rifle stability and shooting accuracy among novice rifle shooters. Scand J Med Sci Sports. 2007 April;17(2):180185. doi: 10.1111/j.1600-0838.2006. 00549.x.

13. Ratcheva T, Stambolieva K, Kostadinov K. Posturograph with positionsensitive detector and method for it's preparing. BG Patent \#61749,1999. http://worldwide.espacenet.com/public ationDetails/originalDocument?CC $=$ BG\& $\mathrm{NR}=61749 \mathrm{~B} 1 \& \mathrm{KC}=\mathrm{B} 1 \& \mathrm{FT}=\mathrm{D} \&$ date $=1998$ 0529\&DB $=E P O D O C \& l o c a l e=e n \_E P$.

14. Stambolieva K. Fractal properties of postural sway during quiet stance with changed visual and proprioceptive inputs. J Physiol Sci. 2011 Mar;61(2):12330. doi: 10.1007/s12576-010-0129-4.

15. Granat MH, Kirkwood CA, Andrews BJ. Problem with the use of total distance travelled and average speed as measures of postural sway. Med Biol Eng Comput. 1990 Nov;28(6):601-2. 
16. Prieto TR, Hoffmann R, Lovett $E$, et al. Measures of postural steadiness: differences between healthy young and elderly adults. IEEE Trans Biomed Eng. 1996 Sep; 43(9): 956-66. doi: 10.1109/ 10.532130.
17. Era $\mathrm{P}$, Konttinen $\mathrm{N}$, Mehto $\mathrm{P}$, et al. Postural stability and skilled performance - a study on top-level and naive rifle shooters. J Biomech. 1996 Mar; 29(3): 301-6. doi: 10.1016/0021-9290 (95)00066-6. 